\title{
Leitura no Ensino Médio e Orientações Governamentais
}

\author{
Rosemary Lapa de Oliveira*
}

\begin{abstract}
Resumo
O presente trabalho é o resultado do diálogo entre duas pesquisas, distanciadas no tempo: uma de 2006 e outra de 2013, mas aproximadas em relação ao tema e à abordagem. Ambas tiveram metodologia de inspiração etnográfica e buscaram nas escolas de ensino médio respostas a perguntas referentes à formação do sujeito leitor. Os sujeitos de pesquisa foram professoras e estudantes do ensino médio que foram ouvidos em seus etnométodos. Foi realizada uma breve análise histórica dos caminhos pedagógicos do trabalho com leitura no Brasil, a partir da República, e a escuta sensível do que estudantes e professores tinham a dizer. Os resultados apontam para uma evolução lenta, quase imperceptível das mediações docentes feitas em prol da formação do sujeito leitor.
\end{abstract}

Palavras-chave: leitura; literatura; Ensino Médio

\begin{abstract}
This paper is the result of dialogue between the two surveys, distanced in time: one 2006 and other 2013, but approached in relation to the theme and approach. Both had to ethnographic methodology and sought inspiration in high schools answers to questions concerning the formation of the subject reader. The research subjects were teachers and high school students that were heard in their etnométodos. A brief historical analysis of the pedagogical ways of reading with work was carried out from the republic and sensitive listening to what students and teachers had to say. The results point to a slow evolution, almost imperceptible of teaching mediations made in favor of the formation of the subject reader.
\end{abstract}

Keywords: reading; literature; high school

\section{Introdução}

Antes da LDBEN 9394/96, nos anos 1960 a 1980, o Ensino Médio (EM) era voltado para a formação profissional, seja preparando para o ensino superior, seja profissionalizando, pois, naquele cenário, havia uma dualidade: o educando optava por fazer um curso profissionalizante ou continuar os estudos preparatórios para os exames vestibulares, no entanto, seja em uma ou outra modalidade, servia a um mundo do trabalho de estrutura taylorista-fordista própria das linhas de montagem (MAFRA, 2003). Considerando o grande desenvolvimento da industrialização no Brasil, a política

\footnotetext{
* Professora Adjunta do Departamento de Educação da UNEB - Campus I - Salvador-Bahia-Brasil. rosy.lapa@gmail.com
}

Revista Leitura V.2 no 56 - jul/dez 2015 - Número regular - Autor/a: Rosemary Lapa de

Oliveira - p. $26-41$ 
educacional vigente priorizou a formação, no EM, de profissionais capazes de utilizar maquinarias e dirigir processos de produção.

Hoje, as relações de trabalho têm mudado e as consequências dessas mudanças podem ser percebidas na preocupação de órgãos internacionais, e de cada nação de per si, em investir numa educação que atenda ao novo mercado. Nessa ideia, ancora-se a Lei de Diretrizes e Bases da Educação Nacional (LDBEN) quando aponta para um mercado regido pelas novas tecnologias e empreendedorismo. Essas habilidades, por sua vez, exigem uma formação não de acúmulo de conhecimento, mas, segundo os Parâmetros Curriculares Nacionais para o Ensino Médio (PCNEM), de "capacidade de pesquisar, buscar informações, analisá-las e selecioná-las, capacidade de aprender, criar, formular, ao invés do simples exercício de memorização" (BRASIL, 2000, p.16), ou seja, utilizar os conhecimentos de forma autônoma e criativa. Ciente das críticas feitas ao PCNEM e a par das mudanças nele ocorridas, tal documento, neste trabalho, será considerado pelo seu valor sócio político em representar o povo brasileiro, uma vez que um documento oficial do Governo representa seu povo e porque todas as ações avaliativas e de interferência pedagógica na escola pública fazem referência ou alusão a esse documento.

A Constituição de 1988 já pronunciava uma concepção de formação do trabalhador, quando, no inciso II do Art. 208, garantia como dever do Estado a progressiva extensão da obrigatoriedade e gratuidade ao ensino médio. Sendo assim, para adaptar-se a essa nova necessidade do mercado de trabalho, a LDBEN - Lei $\mathrm{n}^{\circ}$ 9.394/96 insere, pela primeira vez na história da educação no Brasil, o EM na educação básica. Assim, o EM deixou de preparar para o mercado de trabalho, o que provocou o fechamento da maioria dos cursos profissionalizantes, e passou a preparar para a continuação dos estudos, tornando o EM propedêutico, visando prioritariamente a formação em nível superior, universitária. Concepção que foi introduzida na LDBEN através do decreto 2.208/97, revogado pelo Decreto $n^{\circ}$ 5.154/04, o qual sofre alterações com a redação dada pelo Decreto $n^{\circ} 8.268$, de 2014, atualmente em vigor e que, em seu Art $1^{\circ}$ prevê a educação profissional técnica de nível médio e a educação profissional tecnológica de graduação e de pós-graduação. Sendo assim, visa desenvolver competências e habilidades que forneçam aos jovens egressos do EM "meios para progredir no trabalho e nos estudos" (Art.22, Lei nº. 9.394/96).

Considerando que o portal da Secretaria da Educação Básica do Brasil, sobre PCNEM, declara que "Foram feitos para auxiliar as equipes escolares na execução de p. $26-41$. 
seus trabalhos",ii, portanto representam as ideias escolhidas como privilegiadas para serem desenvolvidas nas escolas e que a ideia assumida sobre linguagem é de caráter sócio interacionista, pode-se inferir que o Governo Brasileiro, falando pelos cidadãos aos quais representa, dá à linguagem uma dimensão transdisciplinar, a qual, nesse documento, tem papel importante na nova abordagem pedagógica proposta pela reformulação da LDBEN, afinal, naquele documento é dito que "a linguagem é a capacidade humana de articular significados coletivos e compartilhá-los" (BRASIL, 1999, p. 5).

Inserida nesse contexto, a leitura tem se constituído, nas últimas décadas, uma preocupação como componente na formação educacional dos jovens egressos do EM e muitas pesquisas têm sido feitas a esse respeito. Isto porque avaliações internas e externas ao ambiente escolar, promovidas pelo Governo Federal, têm apontado para uma deficiência na competência leitora dos jovens egressos do EM, seja na forma do PISA $^{\mathrm{iii}}$ - Programa Internacional de Avaliação dos Estudantes - que trienalmente avalia os alunos na faixa dos 15 anos, idade em que se pressupõe o término da escolaridade básica obrigatória na maioria dos países participantes desse projeto; seja do Sistema de Avaliação do Ensino Básico (SAEB) ${ }^{\text {iv }}$. Conforme estudo desenvolvido por Batista e Rojo (2003) sabe-se que esses programas são sistemas de avaliação que visam medir os resultados do ensino básico em termos de construção de capacidades e competências:

\footnotetext{
Relatório PISA 2001, p.20 - item 2.1.4 O que é avaliado: c) O letramento em Leitura é a compreensão, o uso e a reflexão sobre textos escritos para alcançar objetivos pessoais, desenvolver $o$ conhecimento e potencial individuais e participar plenamente na vida em sociedade.

Níveis de desempenho em Língua Portuguesa - descritores do SAEB: Nível 3 - estabelecer relações coesivas entre partes do texto, inclusive pelo reconhecimento de tópico e comentário, (...) compreender explicações mais abstratas e metalinguísticas.
}

Os resultados, de um modo geral, têm apontado para problemas nas capacidades e competências leitoras dos jovens brasileiros. Isto significa dizer, à luz das concepções norteadoras de tais programas, que "a maior parte dos jovens avaliados mal consegue localizar informações que podem ser inferidas em um texto" (JURADO 2003 In: BATISTA e ROJO 2003, p. 9,10).

Por esse motivo, a leitura tem se tornado uma preocupação constante tanto nos meios acadêmicos, quanto nos órgãos de educação do governo brasileiro. Para entender 
um pouco o que acontece hoje, nas escolas, no que tange à leitura, vejamos, a princípio, o que nos diz a história, depois o que os documentos oficiais falam sobre isso. Permeando esses discursos, teremos os depoimentos recolhidos em pesquisas de mestrado de cada uma das autoras.

\section{Breve histórico sobre a leitura no brasil republicano}

Para Orlandi (1997), atribuir sentidos é uma característica primordial do humano, pois, segundo ela, com ou sem palavras, diante do mundo, nós interpretamos, atribuímos sentidos, quaisquer que sejam, pois há uma relação com o simbólico que constitui o humano. Tal como explicita essa autora, a leitura faz parte de nosso dia-a-dia de forma tão intensa que acabamos acreditando ser algo "natural" e que não necessitaria de qualquer problematização ou reflexão. Assim, tendemos a pensar que formar leitores é fazer com que nossos alunos e alunas sejam capazes de ler e ponto.

Essa certeza, porém, deixa de existir ao se observar o que outros professores fizeram em outros momentos da história do ensino da leitura. Nesse caso, percebe-se que não se entendia a formação de leitores do mesmo modo que se entende hoje, pois as finalidades que hoje são atribuídas ao ensino da leitura eram diferentes e, muitas vezes, quando adotamos certas práticas e metodologias para o aprendizado da leitura, damos continuidade a antigas concepções de formação de leitores, com as quais usualmente discordamos.

No final do século passado e no início deste, a expansão da escolarização deu-se gradativamente, tornando-se uma das metas do governo republicano, instalado em 1899. Várias reformas de ensino começaram a ser propostas e novos métodos e teorias educacionais passaram a ser difundidos. Apesar dessas iniciativas, muitas vezes a escola, em seu cotidiano, continuava muito semelhante ao que havia sido para as gerações anteriores: espaços mal iluminados, mobiliário precário, professores mal remunerados e, muitas vezes, improvisados faziam parte do cotidiano escolar. Um cenário ainda presente em várias escolas brasileiras.

Os castigos físicos norteavam a ação escolar e os alunos, todos na mesma sala, eram agrupados pelo nível de instrução que possuíam. Essa medida era dada pelo livro didático, através do nível de leitura em que cada um se encontrava. O professor não dava aulas, como hoje estamos acostumados a pensar, mas "tomava" a lição de cada um dos alunos, fazendo-os ler em voz alta. Portanto a leitura, parece, estava ligada à p. $26-41$. 
decodificação do código vocabular, à fonética e prosódia. Aprendia-se a ler, na escola, para mostrar essa leitura em público.

A oferta de leitura na escola era muito restrita, geralmente ligada ao livro didático, o qual trazia, conforme vimos no capítulo anterior, apenas textos canônicos, de autores já mortos e, inicialmente, na sua maioria, de autores portugueses. Os objetos disponíveis para a leitura, não só na escola, mas nas diversas instâncias sociais, eram raros e poucos eram os lugares em que se podiam adquirir esses objetos, pois bibliotecas e livrarias só existiam nas cidades mais populosas. Por conta disso e aliado ao fato de poucas pessoas frequentarem a escola, havia poucos leitores.

Graciliano Ramos, em Infância, narrativa autobiográfica de sua meninice na virada do século XIX para o século XX, conta que sentia dificuldades para entender as lições, e o livro da escola chegava a lhe provocar náuseas. As horas de leitura eram, para o menino, horas de tortura. O mesmo menino que, depois de entrar em contato com algumas obras literárias fora da escola, passou a buscar com ânsia e prazer outros objetos de leitura na pequena cidade em que morava, no sertão pernambucano. Havia se tornado leitor, a despeito das práticas escolares, simplesmente por ter acesso aos livros.

Provavelmente a leitura tenha provocado náuseas no pequeno Graciliano por ter uma linguagem fora de seu tempo, pois é tradição entre os compêndios, transcrever os textos conforme os autores o escreveram em seu tempo, muitas vezes tão atemporal que torna a "linguagem mais complexa e a leitura difícil" conforme chama atenção um alunos do ensino médio, em depoimento colhido para compor corpus de trabalho de pesquisa de mestrado (CAMPINHO, 2006).

José Lins do Rego, em Doidinho, romance autobiográfico que narra sua vivência em um internato no início do século, registra momentos de angústia ao ler para o seu professor as lições do livro escolar. Mas, apesar do sofrimento que marcou, no geral, a sua relação com os objetos de leitura escolares, o futuro escritor confessa a ampliação de horizontes proporcionada por eles, fazendo-o conhecer outros mundos e a relativizar o seu. Em alguns casos, a leitura também provocava prazer, apesar das práticas escolares não terem essa intenção e, de modo geral, a relação entre leitura e prazer era vista como danosa.

As oportunidades de leitura escolares tinham em vista formar leitores não propriamente para desenvolver as competências e usos da leitura, mas antes, provavelmente, o que se buscava na formação de leitores era a transmissão de conteúdos instrutivos, em geografia, história, ciências e habilidades básicas de leitura e escrita e p. $26-41$. 
das regras ortográficas do Português, além da transmissão de regras e modelos de comportamento vigentes na época.

Ainda é possível verificar esse modo de ver a leitura nas salas de aula da atualidade, conforme denuncia Gramacho (2013, p. 15) em sua dissertação:

\begin{abstract}
A questão que me incomodava e ainda me incomoda é o fato de o texto literário - o de arte, objeto de leitura, de lazer, de apreciação estética, de deleite, de produção de sentidos, de diálogo com a vida, aparecer sempre como abonação; como um apêndice ao estudo de literatura proposto pelos autores.
\end{abstract}

Isso acontece a despeito do fato de que a sociedade começou a se tornar mais complexa e as demandas em torno da escolarização aumentaram significativamente. Entre as décadas de 1920 e 1950 mais postos de trabalho surgiram, outros costumes culturais foram adotados: a instrução e a educação passaram a ser vistas como necessárias ao desenvolvimento econômico e cultural do país e um dos signos da "civilidade." Nesse novo cenário, várias reformas de ensino foram empreendidas, tentando mudar o triste marco de o Brasil chegar ao século XX com mais de $80 \%$ da população analfabeta. Durante as reformas, a rede pública de ensino expandiu-se enormemente. Novos métodos de ensino foram discutidos no país, sob a forte influência do movimento da Escola Nova. Novos modos de ler e inovadores papéis passaram a ser atribuídos à leitura na escola. A leitura silenciosa, por exemplo, passou a ser prescrita não só na escola, mas em outras instâncias da sociedade e a cada dia lia-se menos coletiva e oralmente.

Com a progressiva introdução da leitura silenciosa e rápida, da busca do significado do texto, em detrimento da memorização do texto e de seus conteúdos, antes valorizados, com o progressivo abandono da doutrinação moral e ideológica e a progressiva introdução de novos gêneros de textos e de impressos nas salas de aula, essas práticas e objetos de leitura restritos foram gradualmente sendo ampliados. No entanto, o que se via era ainda uma canonização do texto e do autor, "uma concepção de língua como representação do pensamento e de sujeito como senhor absoluto de suas ações e de seu dizer, o texto é visto como um produto - lógico - do pensamento do autor" (KOCH, 2003, p. 16). Essa concepção preconiza um leitor passivo ao qual cabe captar a representação mental, juntamente com as intenções do produtor do texto. E a interação entre sujeito autor e sujeito leitor que permite a esse participar da arte do texto e compreendê-lo como um processo estético de interlocução, como um sistema textual p. $26-41$. 
destinado à interatividade, prevista enquanto proposta pelos vazios do próprio texto se perde, pois, segundo Gramacho (2013, p. 18)

Cria-se ao mesmo tempo uma ponte e um abismo entre um real social representado ficcionalmente - representação esta que, entre outras dimensões sociais, impõe uma necessidade de interpretação coerente pelo leitor - e a dimensão imaginária envolvida na leitura.

O saldo positivo, até aqui, é que o público leitor cresceu e se diversificou. Mas, apesar de todo esse movimento "inovador" na produção intelectual sobre a leitura escolar, o dia-a-dia da maioria das escolas continuava sem muitas inovações: os alunos continuavam temerosos em ler as lições, ainda tomadas em voz alta, e a angústia e o tédio continuavam a marcar a sua relação com a leitura prescrita pela escola.

Em muitas escolas, alguns objetos de leitura chegaram a ser proibidos - como as histórias em quadrinhos, que fascinaram crianças e jovens dos anos 1930 e 1940. A despeito da proibição, da censura, havia - e ainda hoje há - uma grande circulação de objetos de leitura entre os alunos, independente do que a escola prescreve.

Entre as décadas de 1950 e 1970, cada vez mais se desenvolviam métodos alternativos de ensino: surgiram as escolas experimentais e a ideia de um ensino centrado no aluno e nas suas necessidades. A rede pública de ensino se expandia de modo muito rápido: cada vez mais as camadas populares ingressavam na escola. Porém, muitas escolas continuaram a adotar antigos comportamentos e métodos, tornando desagradáveis e temidos os momentos em que as práticas de leitura se davam. Nesse período, aumentaram também os meios de acesso à leitura: bibliotecas populares, inclusive ambulantes, foram criadas em muitas cidades do país e o número de livrarias também aumentou significativamente.

A partir década de 1970, há uma necessidade de atualização do conteúdo, cada vez mais rápida, por conta do desenvolvimento de pesquisas que modificam o conhecimento pedagógico e do ritmo da vida social que se modificou muito com a popularização da mídia jornalística pela televisão. Com uma produção cada vez maior e mais diversificada, as obras destinadas aos leitores e leitoras infanto-juvenis passam a fazer parte, ao lado dos livros de leitura, das atividades de leitura escolar: esse tipo de literatura também se escolariza, ou seja, um controle exercido pela escola sobre o que e como se deve ler. Nesse sentido, o texto sai de seu contexto de circulação e se presta a objetivos meramente didáticos externos à sua produção e continuamos na expectativa de 
poder "virar o jogo": partilhar leitura da arte com arte, não apresentar fragmentos da arte como abonação, como exemplificação de características de escolas literárias e, assim, formar cidadãos para o mercado de trabalho também, mas, principalmente, para a vida.

Mais recentemente, e a cada dia de maneira mais intensa, procura-se tornar presentes, nas escolas, os usos sociais da língua escrita, na diversidade dos modos de ler e na diversidade dos gêneros e dos portadores ou suportes de textos. O livro didático é colocado em xeque pelo emprego do jornal, do livro, da revista e de todo um conjunto de textos cuja presença era proibida na escola: quadrinhos, rótulos, listas, quadros e tabelas, placas, publicidade. Ao lado disso, livros e artigos têm surgido, buscando auxiliar as professoras na tarefa de tornar seus alunos e alunas, leitores e leitoras. Cada vez mais fala-se na alegria de ler, no prazer provocado pela leitura. Pontualmente alguns docentes permitem, algumas vezes, que seus discentes sugiram um livro para leitura e discussão, no entanto, essa prática é feita mais no sentido da concessão e as concessões, concordemos, são pontuais, são acordos temporários. Esse princípio não se mantém.

Estudos e pesquisas que procuram analisar o cotidiano da escola - em seu passado e em seu presente - mostram que, a despeito de todos esses fatores de mudança e transformação, as práticas escolares tendem a restringir fortemente a oferta de leitura e a formação de leitores. Esses estudos indicam que os professores e as professoras mesmo numa época de diversificação da produção editorial brasileira - tendem a selecionar textos que evidenciem uma forte preocupação com a formação moral e ideológica de seus alunos ou com o aprendizado de estratégias de escrita de gêneros e aspectos gramaticais. Esses mesmos estudos mostram também que muitas professoras e seus alunos lêem os textos, buscando, ao final de sua leitura, descobrir qual teria sido a lição da história, seu principal ensinamento ou exemplo, evidenciando uma concepção de língua e linguagem como código transparente e possuidor de uma interpretação que é a correta. Por fim, esses estudos mostram que o prazer da leitura é algo ainda muito distante da maior parte das escolas e que os alunos tendem a ver suas aulas de leitura de maneira não muito diferente da de Graciliano Ramos: "horas de tortura e aborrecimento".

Para um melhor entendimento das considerações feitas doravante, faz-se necessário estabelecer definições sobre leitura individual e leitura pedagógica. A leitura individual é aquela em que o leitor interage com a leitura por razões outras que não as pedagógicas do ambiente escolar.

Revista Leitura V. 2 n 56 - jul/dez 2016 - Número regular - Autor/a: Rosemary Lapa de Oliveira p. $26-41$. 
Por falta de uma designação mais adequada, tomaremos a definição de leitura pedagógica - conduzida pedagogicamente no ambiente escolar -, pois cabe principalmente à escola desenvolver as capacidades e habilidades concernentes à produção de leitura, à formação do leitor crítico e independente. A leitura pedagógica é tomada, aqui, como produção de leitura, ou seja, observação, análise, reflexão, planificação, tomada de decisão e, finalmente, ação. Ela costuma ser concebida em dois estágios: leitura decifratória ou de decodificação, aquela em que a atenção e o esforço do leitor se dissipam principalmente na decifração, no esforço de decodificar o código escrito e a leitura crítica, em que se emprega pequeno esforço na decifração e que supõe um leitor crítico. Ambas as leituras visam, ou deveriam visar, o enleituramento, termo cunhado em pesquisa de doutoramento que aponta para a capacidade de tornar-se leitor de forma ampla, tendo na leitura uma ação que é contínua e ampliada a cada contato com o contexto que cerca o sujeito-leitor (OLIVEIRA, 2013, p. 36).

Os instrumentos que estabelecem diretrizes sobre o fazer pedagógico referente à língua e à linguagem trazem uma concepção interacional de leitura, na qual o texto é considerado um lugar de trocas e o autor e leitor passam a ser interlocutores que se constituem e são constituídos no ato de ler. Nessa perspectiva, a leitura é uma atividade interativa e de construção de sentidos na interação texto-sujeitos. Portanto as orientações para a aula de leitura, atualmente, preconizam o desenvolvimento da autonomia intelectual e do pensamento crítico e, para isso, é necessário que o leitor interaja com o texto.

Nas práticas de sala de aula, atualmente, percebe-se situações diversas como as descritas por alunos em entrevista colhida em pesquisa de mestrado por Campinho (2006, p. 63):

Ela chega, ela senta, aí faz tipo uma... coloca os alunos ao redor dela, aí lê e manda as outras pessoas lerem, entendeu? Aí os assuntos que ela passa de dever de casa, não coloca no caderno não, que ela não cobra a gente no caderno, ela responde, entendeu? Ela mesma vai falando e respondendo, tudo com a gente (Aluno 6).

Tanto nesse depoimento em particular como em outros colhidos nessa mesma turma de EM, nota-se a falta de referência a um trabalho pedagógico voltado para a produção de leitura que vise a autonomia do leitor, ou seja, o enleituramento. A leitura explorada pela professora parece ser a decifratória, de decodificação do signo linguístico o que não cabe a uma turma de EM. Então ler o texto, sem considerar a sua p. $26-41$. 
textualidade, possibilidade de análise, de reflexão, de planificação em nada contribui para a formação de um leitor autônomo.

Ela sempre bota a gente pra ler, quer dizer, quem quiser ler, né. fala as páginas que é pra ler, se a gente quiser ler a gente lê, e assim... explica tudo, os pontos parágrafo, coisa assim que é pra gente ler, coisa assim (aluno 8) (CAMPINHO, 2006, 63).

Mais uma vez, no excerto acima, temos um exemplo de concepção de leitura decifratória com uma informação a mais: pode-se inferir que a professora demonstra que se preocupa com outros aspectos de leitura como postura, prosódia, uma vez que pede para que os alunos leiam. No entanto, é importante considerar que esse tipo de leitura está muito aquém do que se espera de alunos egressos do EF. Pelo depoimento, observa-se que uma leitura pedagógica de atribuição de sentidos ao texto, de desenvolvimento de habilidades de análise, observação, reflexão, enfim, desenvolvimento de senso crítico e formação de cidadão não fazem parte da prioridade dessa aula, pois a professora "explica tudo" e o tudo que ela ensina está mais ligado à prescrição gramatical que ao uso prático da linguagem. O mesmo não se percebe neste outro depoimento:

(...) a professora passa os textos, né, ela discute muito com a gente, deixa tudo bem claro na nossa mente, é super bom mesmo, reforça mesmo a nossa leitura, assim quem tem preguiça de ler (risos) aí vai lendo... eu gosto dos textos também, é fácil (aluno 10) (CAMPINHO, 2006, p. 63).

Pode-se inferir que essa professora promove um trabalho que leva à leitura crítica, através de debate sobre o texto com seus alunos, reflexão, tentando favorecer um ambiente para o desenvolvimento de habilidades de leitura enleituramento. O que é mais condizente com um trabalho voltado para o EM, mas que ainda está aquém do esperado para esse ciclo escolar. Falta estímulo à leitura como prática social.

Nos depoimentos acima, com alunos de diferentes professoras, podemos perceber quão diversificado é o trabalho de leitura na escola. Enquanto alguns estão ainda presos à decodificação e textos canônicos, notadamente os dois primeiros, outros já trazem textos do cotidiano e provocam inferências, análises, uma leitura que leva à reflexão e autonomia. 


\title{
Leitura no ensino médio e orientações governamentais
}

Atualmente, há uma preocupação muito grande com relação à leitura e pode-se perceber isso através de alguns projetos incentivados e subsidiados por instâncias governamentais, como por exemplo, Viva Leitura, Tecer Leituras, Gestar, Leituração, entre outros. No entanto, que tipo de leitura é feita na escola? Que concepção de leitura as professoras têm? Nos depoimentos colhidos entre professoras e alunos, foi percebida uma incongruência entre o que a professora diz que faz e entre o que os alunos e as alunas dizem que a professora faz, ressaltando, nessa desavença, uma concepção de leitura que versa em sentido diferente daquelas preconizadas pelas políticas públicas de educação no nosso país. As quais dizem que:

\begin{abstract}
As competências e habilidades propostas pelos Parâmetros Curriculares Nacionais para o Ensino Médio (PCNEM) permitem inferir que o ensino de Língua Portuguesa, hoje, busca desenvolver no aluno seu potencial crítico, sua percepção das múltiplas possibilidades de expressão linguística, sua capacitação como leitor efetivo dos mais diversos textos representativos de nossa cultura. Para além da memorização mecânica de regras gramaticais ou das características de determinado movimento literário, o aluno deve ter meios para ampliar e articular conhecimentos e competências que possam ser mobilizadas nas inúmeras situações de uso da língua com que se depara, na família, entre amigos, na escola, no mundo do trabalhov .
\end{abstract}

Portanto, podemos dizer que as orientações governamentais versam sobre um leitor autônomo, capaz de atribuir sentidos aos textos e de dialogar com eles de forma crítica, ou seja, que sejam capazes de enleiturar-se. Dessa forma, tais orientações determinam uma concepção de texto que, por conta de vários fatores, tais como: formação docente, situação social do docente, situação global do discente, entre outros tantos tangíveis e intangíveis, está longe daquela praticada pelas professoras, e impõem um fazer em sala de aula para o qual as professoras talvez não estejam preparadas. No entanto, nota-se o silenciamento das docentes diante do dizer acadêmico institucionalizado através do discurso da autoridade, reorganizando o seu dizer para se aproximar do desejável pelas autoridades:

PROFESSORA 1: (...) você sabe que leitura e escrita são interligadas: não adianta apenas saber ler. Tem que haver criticidade ao ver o mundo, o seu mundo, o mundo lá fora, relacionar, entender os problemas e também ler por prazer, então como trabalhar esse prazer? O aluno hoje em dia, com a competição, com a internet, com a coisa 
fácil, não têm o prazer do livro, preferem até ler livros, quem tem acesso, através dos computadores. Então eu pergunto: será que poderão levar esses livros em ônibus pra ler ou em momentos vagos? (CAMPINHO, 2006, p. 122).

Nota-se um discurso em defesa do livro, como se a leitura fosse apenas a da literatura, uma ideia, por sinal, que faz parte da cultura escolar e já é tradição. A professora relaciona a ideia de criticidade, o "ver o mundo, o seu mundo lá fora" com o livro. Num mudo tão globalizado, a leitura escolar não pode se restringir, e não se restringe, ao livro, é necessário fazer a leitura de textos do cotidiano.

Uma estagiária que participou da pesquisa acima apontada relata a seguinte fala de um aluno, após a leitura, segundo ela, feita com dificuldade por ele. Importante registrar que há momentos em que é feito o registro de que os alunos têm dificuldade em ler, no sentido de decodificar o escrito, outras há em que a dificuldade reside em atribuir sentidos ao texto. Nesse caso, em particular, foi notada a dificuldade em decodificar a linguagem usada no texto, pois esse se insere na escola romântica, tão longe da realidade linguística atual, tão longe da realidade cotidiana do aluno, sem conhecimento prévio de tal estilo de linguagem. Assim relata a estagiária: "É difícil ler poesias como esta porque as pessoas da época eram muito inteligentes" (CAMPINHO, 2006, p. 122). Nota-se, nessa fala, a forte influência de uma ideologia imposta às classes mais baixas da sociedade de que os seus conhecimentos são desprezíveis e de que há um modelo de inteligência associada aos cânones. A observadora relata que a professora contestou a fala de seu aluno e debateu o assunto, um procedimento que aponta para a minimização da situação apresentada, porém não há referência sobre uma mediação da interpretação do texto que leve à crítica social, ao diálogo do leitor com o texto, produzindo leitura e atribuição de sentidos.

De um modo geral, as professoras têm explicitada a ideia da leitura que extrapola a decifração do código, que preconiza um leitor autônomo, um leitor de mundo:

PROFESSORA 3: O mais importante para mim é o trabalho com leitura, interpretação e produção de textos, pois através do domínio dessas habilidades o indivíduo se torna capaz de fazer uma leitura do mundo de forma eficiente, além de construir o seu conhecimento (CAMPINHO, 2006, p. 123). 
No entanto, o que se evidencia nos relatos dos alunos é uma prática destoante da realidade apresentada pelas professoras, em que a leitura é parafrástica, ou seja, reprodução/ reformulação do sentido dado pelo texto-fonte para a produção de um texto-derivado (ORLANDI, 2001) e/ou de decodificação. Para os alunos consultados, a concepção de leitura corresponde à decodificação do código gráfico, isto é, para eles ler é saber decifrar as palavras e os sinais gráficos, tanto as marcas de prosódia, quanto as marcas estilísticas de pausa e entonação que as acompanham.

(...) ela sempre bota a gente pra ler, quer dizer, quem quiser ler, ler, né. mas ela sempre bota a gente pra ler. Fala a página que é pra ler se a gente quiser ler a gente lê, e assim... explica tudo, os pontos parágrafo, coisa assim que é pra gente ler, coisa assim (aluno 8) (CAMPINHO, 2006, 123-124).

Para efeitos de análise, podemos inferir que se o aluno não se reporta a um estudo de leitura que promova o diálogo e o pensamento crítico e divergente, é porque ele não existe. Assim, a professora não promove o enleituramento, pelo contrário silencia outros sentidos atribuíveis à leitura quando ela "explica tudo". Além de silenciar a sua própria leitura ao engajar-se na leitura proposta no livro didático:

Ela chega... pede boa noite, é claro, fala: "hoje vamos trabalhar com o Barroco, abra o livro em tal página", aí começa a leitura, ela explica, pergunta as dúvida da gente, se a gente tem dúvida em alguma coisa, explica a gente... é isso (aluno 7) (CAMPINHO, 2006, 124).

Portanto, diante do exposto, podemos dizer que a leitura no EM caminha entre o que se diz, ou seja, o desejável perante as possibilidades que alunos egressos de, no mínimo, onze anos de aulas de leitura deveriam apresentar, ou o previsto entre as orientações governamentais e o que se faz, ou seja, o que a professora consegue desenvolver em sala de aula, levando em conta as suas próprias limitações e as limitações dos alunos. Mas não se consubstancia enquanto atividade visceral da aula de Língua Portuguesa e Literatura e, nisso, se perde o texto literário e suas possibilidades estéticas, artísticas e de ampliação de conhecimento de mundo.

\section{Algumas reflexões a título de conclusão}


Conforme o exposto, vimos uma tendência de apagamento da voz do professor, atrás de políticas paternalistas de apresentar normas e procedimentos, além do próprio planejamento da aula, através do livro didático. Geralmente as pesquisas desenvolvidas em ambiente escolar apontam para a má formação do docente, mas, se esse é o problema, por que não investir em formação de mais qualidade, ao invés de "amparálos" em sua má formação? Uma possível leitura que se faz desses todos discursos é de descrença por esse profissional. Em $\mathrm{AD}$ discute-se que a prática científica não está segmentada da prática política e vice-versa. Ambas são determinadas pelas condições sócio-históricas e ideológicas de uma dada formação social. Nessa visão, o discurso dos cientistas da linguagem que assinam as orientações governamentais nada mais é do que o discurso do poder impondo metas e objetivos a serem alcançados, industrializando a escola, um espaço que deveria ser o da construção de conhecimento.

Aos alunos, é reservado espaço ainda mais silencioso do que o do professor. Enquanto esse ainda é chamado para dar a sua opinião, àquele só resta calar e aceitar. Orlandi (2001) adota a posição de que "somos sujeitos simbólicos vivendo espaços histórico-sociais", mas essa concepção que promove a formação do sujeito para o mundo do trabalho, ou seja, para a sua inserção crítica e produtiva na sociedade, não se revela na escola de EM, não nas aulas de Literatura, nas quais também deveriam estar.

Para formar o cidadão para o mundo do trabalho, ou seja, para a sua inserção crítica e ativa na sociedade, será preciso muito mais que insistir em centrar-se na decifração do código linguístico de forma pontual e definitiva. É preciso que o enleituramento faça parte central dos planejamentos de aula também dos professores de Língua Portuguesa e Literatura no ensino médio, ressaltando a carga político ideológica de que são feitos os textos literários e sua capacidade de promover uma releitura do mundo.

Se assim não ocorre, então, como exigir dos alunos a capacidade leitora de "analisar, raciocinar e refletir ativamente sobre seus conhecimentos e experiências, enfocando competências que serão relevantes para suas vidas futuras", como propõem o PISA (BRASIL, 2001), ou que "demonstrem habilidades de leitura de textos argumentativos mais complexos, relacionem tese e argumentos em textos longos, estabeleçam relação de causa e consequência, identifiquem efeitos de ironia ou humor em textos variados, efeitos de sentidos decorrentes do uso de uma palavra, expressão e da pontuação, além de reconhecerem marcas linguísticas do código de um grupo social" como espera a Prova Brasil (BRASIL, 2004), se, em sala de aula, o estudo do texto não p. $26-41$. 
conduz à consecução desses objetivos? Se, na escola, o aluno é levado a apagar a sua constituição leitora, pois é pouco requisitada? Se a voz do professor é apagada da cena político-educacional e esse profissional é alijado de atuar ativamente nas decisões que concernem ao ensino?

\section{Referências}

BATISTA, Antônio Augusto Gomes. ROJO, Roxane (Orgs). Livro didático de língua portuguesa, letramento e cultura escrita. Campinas, SP: Mercado de Letras, 2003.

BRASIL, INEP. Resultados do SAEB 2003 Brasil e Bahia. Brasília - DF, junho 2004 http://www.fnde.gov.br/home/index.jsp?arquivo=/ld_ensinomedio/ld_ensinomedio.html BRASIL, MEC/INEP Relatório Nacional PISA 2000. Brasília, DF: MEC, dez. 2001.

BRASIL, MEC/SEMTEC Parâmetros Curriculares Nacionais. Brasília, DF: MEC, 1999.

BRASIL, MEC/SEMTEC Parâmetros Curriculares Nacionais - Ensino Médio. Brasília, DF: MEC, 2000.

CAMPINHO, Rosemary Lapa de Oliveira. A introdução do livro didático nas aulas de leitura no ensino médio da rede pública de ensino: um estudo de cunho etnográfico. 2006. 142f. Orientadora Profa. Dra. América Lúcia Silva César. Dissertação de mestrado. Universidade Federal da Bahia, Instituto de Letras, Salvador, 2006

GRAMACHO, Regina Lúcia de Araújo. Literatura e ensino: professores e poetas na construção de saberes. 2013. 136 f. Orientadora Profa. Dra. Mary de Andrade Arapiraca. Coorientadora Pra. Dra. Lícia Maria Freire Beltrão. Dissertação mestrado. Universidade Federal da Bahia. Faculdade de Educação, Salvador, 2013

JURADO, Shirley G de O G. Leitura e letramento escolar no ensino médio: um Estudo exploratório. 2003. 150 p. Dissertação de Mestrado. Programa de Pós-Graduação em Linguística Aplicada. PUC-SP.

KOCH, Ingedore Villaça. A inter-ação pela linguagem. 8. ed. São Paulo: Contexto, 2003

MAFRA, Núbio Delanne Ferraz. Leituras à Revelia da Escola. Londrina - PR: Eduel, 2003

OLIVEIRA, Rosemary Lapa de. A leitura-estar-no-mundo e a constituição do sujeitoleitor. 2013. 158f. Orientadora Profa. Dra. Dinéa Maria Sobral Muniz. Tese doutorado. Universidade Federal da Bahia. Faculdade de Educação, Salvador, 2013

Revista Leitura V.2 n 56 - jul/dez 2016 - Número regular - Autor/a: Rosemary Lapa de Oliveira p. $26-41$. 
ORLANDI, Eni Puccinelli. As formas do silêncio: no movimento dos sentidos. 4.ed. Campinas, SP: Editora da UNICAMP, 1997

ORLANDI, Eni Puccinelli. Discurso e Texto: Formulação e Circulação dos Sentidos. Campinas, SP: Pontes, 2001.

RAMOS, Graciliano. Infância. 23ed. São Paulo: Record, 1986.

REGO, José Lins do. Doidinho. 16ed. Rio de Janeiro: José Olympio, 1977.

*Doutora em Educação, Mestre em Letras e Linguística, Graduação em Letras, Professora Adjunta DE do Departamento de Educação da UNEB - Campus I Salvador.

**Mestre em Educação, Professora nível 3 da Secretaria de Educação do Estado da Bahia - Aposentada. Professora de Curso de Especialização UFBA.

\footnotetext{
${ }^{\mathrm{i}}$ http://www.planalto.gov.br/ccivil_03/_ato2004-2006/2004/decreto/d5154.htm Acesso em 25 jun 2015

ii http://portal.mec.gov.br/index.php?option=com_content\&id=12598:publicacoes Acesso em 24 jun 2015

iii http://www.oecd.org/pisa/ Acesso em 25 jun 2015.

${ }^{\text {iv }}$ http://portal.inep.gov.br/saeb Acesso em 25 jun 2015

${ }^{\vee}$ Capturado em > http://portal.mec.gov.br/seb/arquivos/pdf/linguagens.pdf, Acesso em 01/10/2014.
} 